\title{
ARUS SELATAN JAWA
}

\section{Oleh \\ Dewi Surinati ${ }^{1)}$ dan Jaka Harry Mulyanto Wijaya ${ }^{2)}$}

\begin{abstract}
SOUTH JAVA CURRENT. Indian Ocean is influenced by the monsoon cycle. Monsoon cycle that occurs in the Indian Ocean influences the current patterns. Since a very strong westerlies occurs in The Tropical Convergence Zone (TCZ) at the equator, wyrtki jet is formed in the $40^{\circ}-80^{\circ} \mathrm{W}$ Indian Ocean on a transitional season. Its branchs are possibly formed when the wyrtki jet is in the equatorial west coast of Sumatra to the north and south along the western coast of Sumatra which eventually creates South Java Current (SJC). SJC flows southeastward during December-April and northwestward during June-October, when it is associated with coastal upwelling. SJC develop upwelling on a seasonal basis.
\end{abstract}

\section{PENDAHULUAN}

Perairan selatan Jawa merupakan perairan Indonesia yang berhubungan langsung dan dipengaruhi oleh Samudera Hindia, perairan Barat Sumatera dan juga Selat Sunda. Oleh karena itu, menurut Hakim (2012), kondisi perairan selatan selalu dinamis sehingga patut untuk dikaji lebih mendalam agar potensi yang terkandung dapat dimanfaatkan sebaik mungkin.

Dinamika oseanografi perairan di selatan Jawa dipengaruhi oleh keterkaitan yang kompleks antara gaya penggerak jauh (remote forcing) dari bagian ekuator Samudra Hindia serta pengaruh lokal yang kuat. Faktor-faktor yang memengaruhi dinamika perairan selatan Jawa yaitu Indian Ocean Dipole (IOD), El Nino Southern Oscillation (ENSO), gelombang kelvin serta arus lintas Indonesia (ARLINDO).

\section{ARUS}

Arus merupakan perpindahan massa air dari satu tempat ke tempat lain, yang disebabkan oleh berbagai faktor, seperti gradien tekanan, hembusan angin, perbedaan densitas, atau pasang surut (Azis, 2006). Menurut Azis (2006), sirkulasi dari arus laut terbagi atas dua kategori yaitu sirkulasi di permukaan laut (surface circulation) dan sirkulasi di dalam laut (intermediate or deep circulation).

Pariwono (1999) mengatakan bahwa di sebagian besar perairan, faktor utama sirkulasi arus permukaan yang menimbulkan arus relatif kuat adalah angin. Arus yang disebabkan oleh angin pada umumnya bersifat musiman, dimana

\footnotetext{
1) Pusat Penelitian Oseanografi, LIPI

${ }^{2)}$ Fakultas Perikanan dan Ilmu Kelautan, Universitas Brawijaya
} 
pada satu musim arus mengalir ke satu arah dengan tetap dan pada musim berikutnya akan berubah arah sesuai dengan perubahan arah angin yang terjadi. Letak geografis perairan Indonesia yang berada pada sistem Angin Muson menyebabkan kondisi oseanografi di perairan tersebut dipengaruhi oleh sistem Angin Muson. Sirkulasi di dalam laut didominasi oleh perbedaan densitas (Oktavia et al., 2011). Perbedaan densitas terjadi karena berubahnya suhu dan salinitas massa air laut.

\section{ARUS SELATAN JAWA (SOUTH JAVA CURRENT)}

Di sepanjang pantai selatan Pulau Jawa terdapat banyak arus dan gelombang yang melintas, baik yang sifatnya musiman, tengah musiman, atau yang merupakan arus global. Di sana juga terdapat rezim gelombang Kelvin Samudra India (Indian Ocean Kelvin Wave/IOKW) yang memiliki karakter khusus. Di selatan Jawa, gelombang Kelvin merambat sepanjang pantai dari barat ke timur. Karakter gelombang ini di belahan bumi selatan ditunjukkan dengan posisi garis pantai yang berada di sebelah kiri gelombang (Samsudin \& Kaneko, 2004).

Selain itu juga terdapat Arus Selatan Jawa (SJC) yang melintas sepanjang tahun. Arus ini berganti-ganti dari timur ke barat atau sebaliknya sesuai angin musim. Arus SJC yang berasal dari Laut China Selatan menuju Samudra Hindia akan membawa banyak uap air sehingga terjadi banyak hujan di Indonesia. Arus tersebut akan terperangkap di dalam Radius Rossby di pantai. Radius Rossby adalah jarak yang terkait dengan kecepatan dan panjang gelombang Rossby yang terjadi karena pengaruh kemiringan pantai. Arus ini berada pada jarak 120-160 kilometer. Ukuran Radius Rossby berbeda-beda pada setiap perairan. Di selatan Pulau Jawa, Radius Rossby jaraknya 180-200 km dari pantai (Laksmi, 2016).

Di selatan Pulau Jawa juga banyak fenomena akibat interaksi lautan atmosfer. Fenomena musiman, antarmusim, dan fenomena dengan periode lebih panjang seperti El Nino (El Nino Southern Oscillation/ENSO) amat berdampak terhadap transportasi laut dan perikanan tangkap. Pada saat terjadi fenomena El Nino, di Samudera Hindia terjadi Indian-Ocean Dipole (IOD) positif yang ditandai dengan berpindahnya massa air dari timur ke barat. Massa air ini membawa banyak ikan. Saat melewati selatan Jawa, ada gelombang Kelvin yang membawanya dari barat ke timur. Gelombang Kelvin ditimbulkan angin pasat dari barat ke timur yang bertiup kuat, Gelombang Kelvin menyeret kolam panas yang diikuti upwelling yang membawa banyak ikan. Upwelling yang terjadi menyebabkan lapisan termoklin (batas antara massa air hangat dan massa air dingin) menjadi naik. Pada lapisan tersebut banyak terdapat zat hara, sehingga pada lapisan tersebut banyak berkumpul ikan, terutama saat terjadi El Nino. Dinamika pergerakan air di perairan selatan Jawa-Bali dipengaruhi oleh berbagai faktor, antara lain sistem angin muson, fenomena ENSO, dipole mode, Arus Khatulistiwa Selatan (AKS) dan Arus dari pantai barat Sumatera, 
dan selain itu juga dipengaruhi oleh massa air Arus Lintas Indonesia (arlindo) yang diantaranya masuk melalui Laut Timor, Selat Lombok, Laut Sawu dan Selat Sunda (Wyrtki, 1961; Meyers et al., 1995; Quadfasel et al. dalam Tubalawony, 2008). Menurut Quadfasel et al. dalam Tubalawony (2008), AKS disuplai oleh aliran dari kepulauan Indonesia dengan kecepatan arus $1,5 \mathrm{~m} / \mathrm{s}$ dan aliran antisiklon dari selatan yang biasanya lemah dengan kecepatan 0,2$0,5 \mathrm{~m} / \mathrm{s}$. Sumber utama massa air perairan selatan Jawa adalah AKS. Batas utara AKS selalu berubah-ubah sepanjang tahun dimana pada muson tenggara (Juni-Oktober), AKS lebih ke selatan dengan posisi maksimal dicapai pada bulan Agustus yakni pada posisi $16^{\circ} \mathrm{LS}$, sedangkan saat muson barat laut (Februari) AKS lebih ke utara hingga mencapai posisi $7^{\circ}$ LS (Wyrtki, 1961).

Sistem angin muson yang berkembang di atas perairan selatan Jawa-Bali dicirikan oleh pembalikan arah angin secara musiman. Di perairan ini, pada bulan Desember-Maret berkembang angin muson barat laut, sedangkan selama bulan Juni-Oktober, berkembang angin muson tenggara (Wyrtki, 1961). Dampak dari bertiupnya angin muson adalah terjadi pola pergerakan massa air yang berbeda antar musim. Kuatnya pengaruh angin muson di perairan Selatan Jawa Bali terlihat melalui terbentuknya aliran massa air pada lapisan permukaan ke arah tenggara di sepanjang pantai barat daya Sumatera dan ke arah timur di selatan Jawa hingga
Sumbawa selama bertiup angin muson barat laut, dimana aliran massa air ini merupakan salah satu cabang dari Arus Sakal Khatulistiwa Samudera Hindia dan cabang arus ini dikenal sebagai Arus Pantai Jawa (APJ) (Tubalawony, 2008). Berkembangnya angin muson tenggara juga mengakibatkan terjadinya upwelling di sepanjang pantai perairan. Menurut Tubalawony (2008), terjadinya upwelling di sepanjang pantai selatan Jawa sebagai respon terhadap bertiupnya angin muson tenggara. Upwelling di daerah ini berlangsung pada bulan Juni hingga pertengahan Oktober dan pusat upwelling dengan suhu permukaan laut yang rendah dimulai dari perairan Selatan Jawa Timur, kemudian bermigrasi ke arah barat, dan selanjutnya bergerak ke arah barat laut sampai posisi $104^{\circ}$ BT. Migrasi upwelling tersebut sangat tergantung pada perubahan musiman angin yang bertiup sepanjang pantai dan perubahan lintang sebagai parameter Coriolis (Tubalawony, 2008).

Kondisi perairan selatan Jawa sangat dipengaruhi oleh perubahan parameter oseanografi permukaan dan atmosfer dimana arus permukaan yang berasal dari timur mengikuti arah angin yang bertiup secara bertahap sepanjang tahun. Perubahan arus oleh pengaruh angin menyebabkan proses pergerakan lapisan permukaan laut hingga membangkitkan percampuran horizontal (horizontal mixing) yang pada akhirnya arus tersebut akan mendorong terjadinya pergeseran massa angin (Suhana, 2015). 


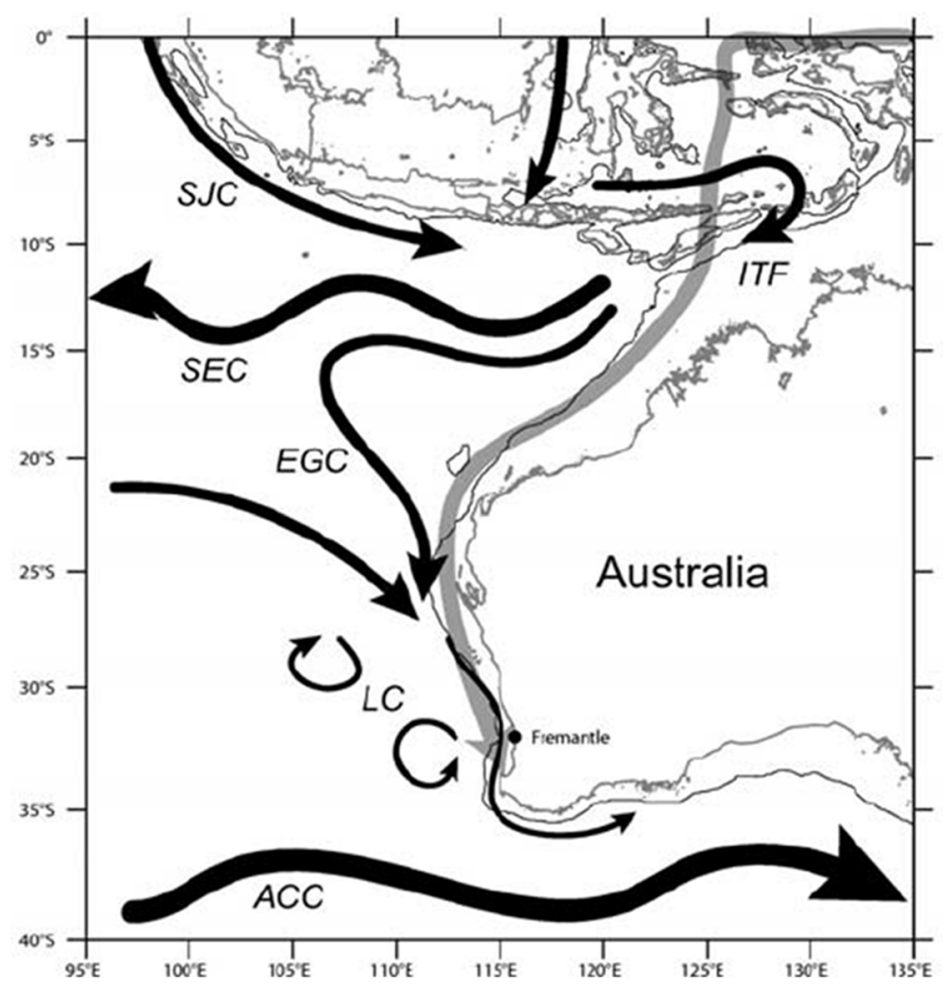

Gambar 1. Skema arus permukaan di sebelah timur-tenggara Samudera (Deng et al., 2008). (ITF: Indonesian Through- flow (arlindo); SEC: South Equatorial Current; SJC: South Java Current; EGC: East Gyral Current; LC: Leeuwin Current; ACC: Antarctic Circumpolar Current)

Variasi pola pergerakan massa air laut di selatan Jawa dikarenakan adanya variasi pergerakan angin sebagai pembangkit utama terjadinya pergerakan massa air laut tersebut (Gambar 1). Di wilayah perairan ini terjadi suatu sistem pola angin yang disebut sistem angin muson Australia-Asia. Menurut Suhana (2015), sistem muson perairan Jawa dicirikan dengan pengembalian arah angin secara musiman yang meyebabkan pola pergerakan massa air yang berbeda. Wrytki (1961), menyebutkan bahwa terjadinya angin muson tersebut, karena terjadi perbedaan tekanan udara antara massa Benua Asia dan Australia. Pada bulan DesemberFebruari di belahan bumi utara terjadi musim dingin sedangkan di belahan bumi selatan terjadi musim panas sehingga terjadi pusat tekanan tinggi di Benua Asia dan pusat tekanan rendah di Benua Australia. Hal ini menyebabkan angin berhembus dari Benua Asia menuju ke Australia. Angin ini pada wilayah selatan katulistiwa dikenal sebagai Angin Muson Barat Laut (Northwest Monsoon). Sebaliknya pada bulan Juli-Agustus berhembus Angin Muson Timur (East Monsoon). 
Adanya pergantian arah muson dua kali dalam setahun menyebabkan pola sirkulasi massa air di lautan juga turut berubah arah. Perubahan arah ini menjadi ciri sirkulasi massa air di perairan Indonesia. Yoga dalam Suhana (2015) menambahkan bahwa selama muson barat laut perairan selatan Jawa mengalami downwelling, sebaliknya selama muson timur mengalami upwelling. Di Selatan Jawa terdapat dua jenis pola pergerakan massa air yakni Arus Katulistiwa Selatan (AKS) atau South Equatorial Current (SEC) dan Arus Pantai Jawa (APJ) (Yoga dalam Suhana, 2015).

\section{Arus Katulistiwa Selatan (AKS) atau South Equatorial Current (SEC)}

Arus Katulistiwa Selatan (AKS) atau South Equatorial Current (SEC) sebagai bagian dari gyre Samudera Hindia yang terbentuk di daerah antara Pantai Selatan Jawa dan Pantai Barat Laut Australia pada umumnya mengalir ke arah barat. Arus permukaan ini menyebar dari barat laut Australia, antara $10^{\circ}-20^{\circ}$ LS hampir ke arah barat Samudera Hindia mencapai Madagaskar (Purba et al.,1992). Arus ini mengalir sepanjang tahun dan menguat pada musim timur. SEC dikenal memiliki beberapa variasi spasial dan temporal di setiap musimnya (Utamy et al., 2015), yakni antara $5^{\circ}-15^{\circ}$ LS selama musim Timur (Gambar 2) dan kisaran $8^{\circ}-18^{\circ}$ LS selama musim Transisi Pertama (Gambar 3).

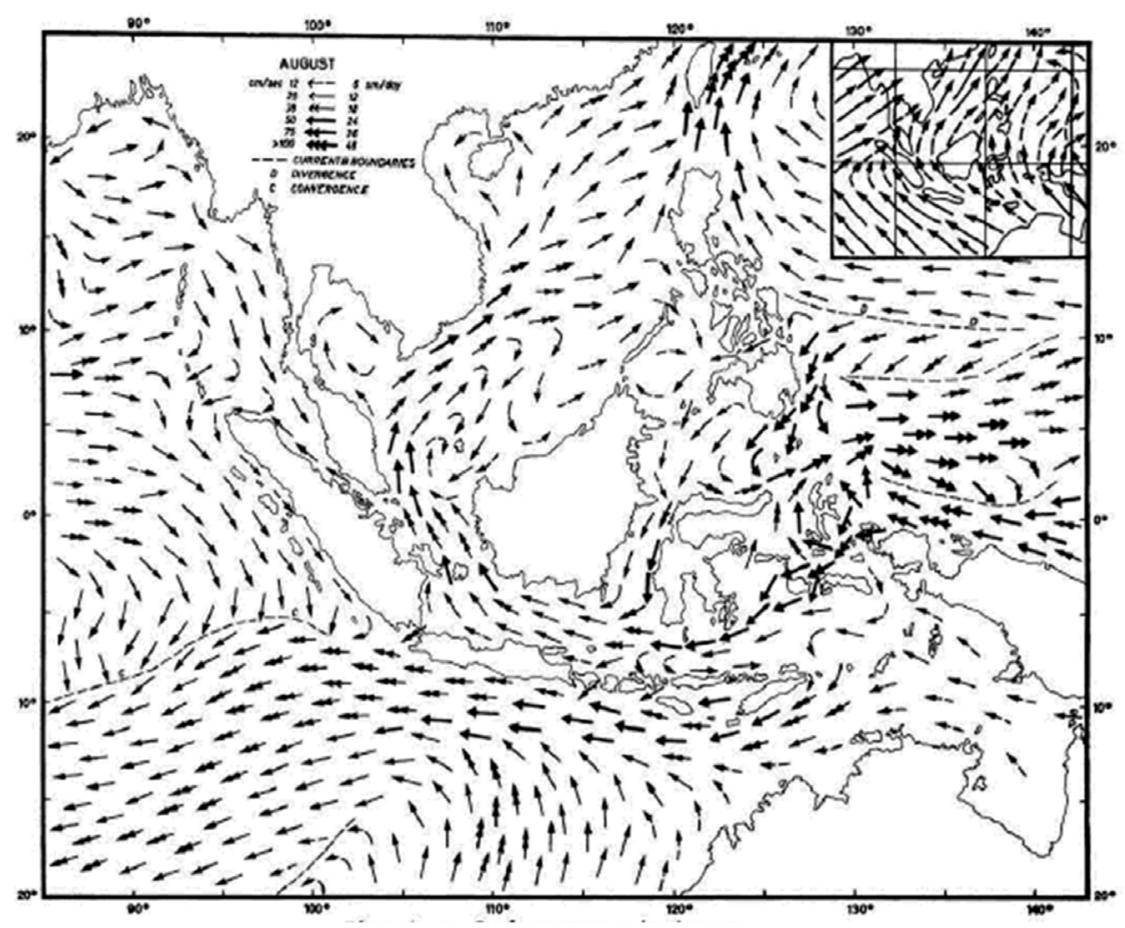

Gambar 2. Pola arus musim Timur (Wyrtki, 1961) 


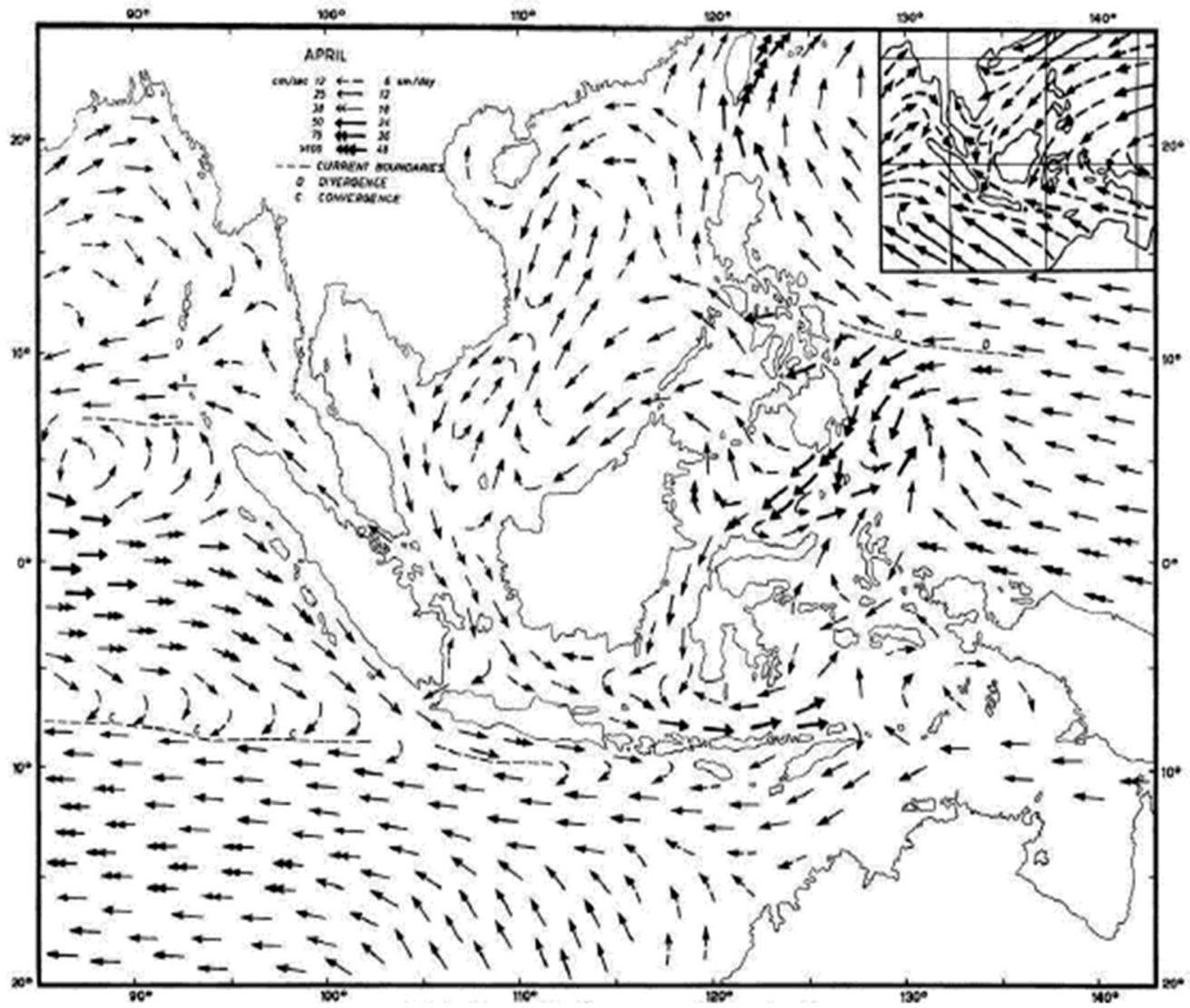

Gambar 3. Pola arus musim Transisi Pertama (Wyrtki, 1961)

Pada Musim Timur, ketika berhembus kuat Angin Muson Tenggara, AKS melebar ke utara melebihi $10^{\circ} \mathrm{LS}$ dan bergerak dari Sumbawa sampai sepanjang pantai selatan Jawa, kemudian berbelok ke arah barat daya (Gambar 2). Angin Muson Tenggara yang bertiup dari tenggara ke arah barat laut menyebabkan terjadinya Transport Ekman yang mengarah menjauhi Pantai Selatan Jawa, maka akan terjadi kekosongan yang berakibat naiknya air (upwelling) dari bawah menuju ke lapisan permukaan. Pada sekitar bulan November, poros AKS berangsurangsur bergerak ke arah selatan dan sepanjang pantai selatan Jawa terbentuk
Arus Pantai Jawa (APJ) dengan arah ke timur (Wyrtki, 1961).

\section{Arus Pantai Jawa (APJ)}

Arus Pantai Jawa (APJ) adalah aliran massa air pada lapisan permukaan dengan arah ke tenggara di sepanjang perairan pantai barat daya Sumatra dan arah ke timur di selatan Jawa hingga Sumbawa (Mbay \& Nurjaya, 2011). APJ terbentuk akibat Arus Sakal Katulistiwa (Equatorial Counter Current) Samudera Hindia yang menerima panas selama pergerakannya menuju Barat Sumatera di sekitar ekuator (Purba et al., 1992). Oleh 
karena itu, APJ memiliki suhu yang lebih hangat. APJ merupakan arus yang sangat penting, karena menyuplai massa air masuk ke perairan bagian selatan Indonesia. Pada sekitar bulan November, poros AKS berangsur-angsur bergerak kearah selatan dan sepanjang pantai selatan Jawa terbentuk Arus Pantai Jawa (APJ) dengan arah ke timur. Kemudian arus ini berbelok ke tenggara menuju ke pantai selatan Jawa. APJ berkembang sampai bulan Juni. Batas antara APJ dan AKS berada di lintang $10^{\circ} \mathrm{LS}$, yang berarti APJ melebar sampai sekitar 90 mil dari pantai (Wilopo, 2005).

Soeriaatmadja dalam Wilopo (2005), menyebutkan bahwa upwelling terjadi pada jarak sekitar 90 mil dari pantai selatan Jawa dan diperkirakan terjadi pada daerah pertemuan antara APJ yang mengarah ke timur dengan AKS yang menuju ke barat. Pada sisi pertemuan kedua sistem arus tersebut, sebagian APJ ikut berbelok ke barat mengikuti AKS.

\section{PENUTUP}

Dua jenis pola pergerakan massa air di perairan selatan Jawa adalah Arus Katulistiwa Selatan (AKS) atau South Equatorial Current (SEC) dan Arus Pulau Jawa (APJ). Arus Katulistiwa Selatan umumnya mengalir ke arah barat. Arus permukaan ini menyebar dari barat laut Australia, antara $10^{\circ}-20^{\circ}$ LS sampai ke arah barat Samudera Hindia mencapai Madagaskar. Adapun Arus Pulau Jawa terbentuk dari poros AKS yang berangsurangsur bergerak ke arah selatan dan sepanjang pantai selatan Jawa dengan arah ke timur, kemudian arus ini berbelok ke tenggara menuju ke pantai selatan Jawa.

\section{DAFTAR PUSTAKA}

Azis, M. F. 2006. Gerak Air Laut. Oseana, 31 (4): 9-21.

Deng, X., C. Hwang, R. Copleman, and W.E. Featherstone. 2008. Seasonal and Interannual Variations of the Leeuwin Current off Western Australia from TOPEX/Poseidon Satellite Altimetry. Terr. Atmos. Ocean. Sci., 19 (1-2): 135-149.

Hakim, B. A. 2012. Karakteristik Kondisi Oseanografi dan Potensinya di Perairan Selatan Jawa Indonesia.. http://dokumen.tips/ documents/karakteristik-kondisi-oseanografi-dan-potensinya. Diakses pada tanggal 28 Maret 2016.

Laksmi, B.I. 2016. Mengenali Arus Pembawa Ikan. http://sains. kompas.com. Diakses pada tanggal 3 April 2016.

Mbay, L.O.N. dan I. W. Nurjaya. 2011. Arus Pantai Jawa pada Muson Barat Laut dan Tenggara di Barat Daya Sumatra. Widyariset, 14 (2): 470-478.

Oktavia, R., J. I Pariwono dan P. Manurung. 2011. Variasi Muka Laut dan Arus Geostrofik Permukaan Perairan Selat Sunda Berdasarkan Data Pasut dan Angin Tahun 2008. Jurnal Ilmu dan Teknologi Kelautan Tropis, Vol. 3 (2): 127-152 
Pariwono, J. I. 1999. Kondisi Oseanografi Perairan Pesisir Lampung. Proyek Pesisir Publication, Technical Report (TE-99/12-I) Coastal Resource Center University of Rhode Island. Jakarta.

Purba, M., I W. Nurjaya dan S. Utaminingsih. 1992. Variasi Suhu Permukaan Laut yang Diukur dengan Satelit NOAA dan Kaitannya dengan Proses Upwelling di Perairan Selatan Jawa. Laporan Penelitian. Fakultas Perikanan IPB. Bogor

Samsudin, F. and A. Kaneko 2004. Numerical and observational estimates of Indian Ocean Kelvin wave intrusion into Lombok Strait. Geophysical Research Letters, 31, L24307, doi:10.1029/2004GL021227: 1-4.

Suhana, M. P. 2015. Sebaran Medan Massa, Medan Tekanan dan Arus Geostropik di Perairan Selatan Jawa Pada Bulan Agustus Tahun 2009. Jurnal Pascasarjana Ilmu Kelautan IPB. Bogor.
Tubalawony, S. 2008. Dinamika Massa Air Lapisan Ekman Prairan Selatan Jawa-Sumbawa Selama Muson Tenggara. Jurnal Torani, 18 (2): 148-159.

Utamy, R.M., N.P. Purba, W.S.Pranowo, and H. Suherman. 2015. The Pattern of South Equatorial Current and Primary Productivity in South Java Seas. International Proceedings of Chemical, Biological and Environmental Engineering, 90 (24): 152-158.

Wilopo, M. D. 2005. Karakter Fisik Oseanografi di Perairan Barat Sumatera dan Selatan JawaSumbawa dari Data Satelit Multi Sensor. Skripsi. Fakultas Perikanan dan Ilmu Kelautan IPB. Bogor.

Wyrtki, K. 1961. Physical Oceanography of The South East Asian Waters. Naga Report. Vol. 2. Scripps Institution of Oceanography. The University of California. La Jolla. California: 195 pp. 